\title{
THE EFFECT OF DEPROTEINIZATION PRIOR TO ENAMEL ACID ETCHING ON PIT AND FISSURE SEALANT SHEAR BOND STRENGTH AND NANOLEAKAGE IN PERMANENT TEETH (IN-VITRO STUDY)

\author{
Omneya M. Mowiena ${ }^{1 \text { BDS }}$, Nadia A. Wahba ${ }^{2 ~ P h D}$, Sonia El-Shabrawy ${ }^{3 P h D}$,
} \\ Dalia M. Talaat ${ }^{4 \mathrm{PhD}}$.
}

\section{ABSTRACT}

INTRODUCTION: Enamel deproteinization before acid etching can be used as a method to improve and enhance the sealant's retentive and sealing ability

OBJECTIVES: To assess and compare the sealant shear bond strength and nanoleakage after placement on etched enamel with and without prior deproteinization.

MATERIALS AND METHODS: Eighty extracted sound human permanent teeth were selected. These were randomly divided into two groups according to the enamel treatment methods, where group A (experimental group): deproteinization prior to acid etching and group B (control group): acid etching without deproteinization. Each group was further subdivided equally into two subgroups ( $\mathrm{n}=20$ ) according to the test used whether shear bond strength and nanoleakage respectively. Shear bond strength test: Shear bond strength was measured using universal testing machine. Mode of failure of each specimen was determined using stereomicroscope. Nanoleakage test: Sealed teeth were then thermocycled, immersed in 50\% silver nitrate solution for 24 hours, sectioned and evaluated quantitatively using energy dispersive x-ray spectrometer (EDX) and qualitatively using scanning electron microscope (SEM). Data were collected, tabulated and statistically analyzed using Mann-Whitney $U$ test $(\mathrm{P}<0.05)$, chi square test and Post-hoc analysis.

RESULTS: The rate of sealant shear bond strength was similar between the two groups ( $\mathrm{P}=0.678)$, but the rate of sealant nanoleakage was significantly lower in the enamel deproteinization group $(\mathrm{P}<0.001)$ than in the control group.

CONCLUSIONS: Deproteinization method prior to enamel acid etching improved shear bond strength and sealing ability of sealants.. KEYWORDS: sealant, deproteinization, shear bond strength, nanoleakage.

1. Bachelor of Dentistry, Faculty of Dentistry, Alexandria University, Alexandria, Egypt.

2. Professor of Pediatric Dentistry, Faculty of Dentistry, Alexandria University, Alexandria, Egypt.

3. Professor of Dental Biomaterials department, Faculty of Dentistry, Alexandria University, Alexandria, Egypt.

4. Associate Professor of Pediatric Dentistry, Faculty of Dentistry, Alexandria University, Alexandria, Egypt.

Corresponding Author

E-mail: omneyamowiena87@hotmail.com

\section{INTRODUCTION}

Dental sealants are regarded as a definitive mode of treatment in the prevention of occlusal caries (1). They are resin materials which are placed in pits and fissures of caries-susceptible teeth forming a micromechanically retained, physically protective layer that blocks the interaction between the cariogenic bacteria and their nutrient substrates, thus eliminating the harmful acidic byproducts and preventing enamel demineralization (2). Bravo et al (3) studied the effect of fluoride and sealant on school children of age 6-8 years old. They found that sealants performed better in caries prevention on occlusal surfaces than fluoride varnishes.

The effectiveness of dental sealant depends on its ability to support an appropriate sealing of pits and fissures, and to stay entirely intact and bonded to the enamel surface without any damage, thus preventing marginal microleakage and the consequent caries progression underneath it (4). So, evaluating the clinical performance of fissure sealants is by assessing their retention and sealing ability. Sano et al (5) introduced nanoleakage to evaluate the sealing ability of sealant, this can be done by using silver nitrate dye for measuring the interfacial leakage.
In an attempt to improve and enhance adhesion, acid etching has been introduced by Buonocore. The quality of etching relies on the etching agent, acid concentration, etching time and composition of the enamel surface (6). Enamel etching converts the smooth enamel surface into an irregular surface with a high surface energy (72 dynes/cm) more than twice that of unetched enamel (7). So, adhesion to enamel relies on achieving the maximum retentive capacity of the surface from the effect of acid etching, and this retentive morphology should be homogeneous over the entire treated surface (8).

However, Hobson et al (9) found that the topographic quality of enamel etching with phosphoric acid (H3PO4) was not accomplished over the total adhesion surface. Also, H3PO4 acts only on the mineralized part of enamel but doesn't eliminate the organic material which compromises less than $1 \%$ (8) but may affect the quality of etching pattern. For this reason, various invasive and non-invasive techniques as sodium hypochlorite (NaOCl) deproteinization have been suggested (10).

Sodium hypochlorite is a non-invasive technique, that has been used in endodontics due to its antibacterial effects and capability to dissolve and remove organic smear layer from the root canal space without doing any harm to tooth 
structure (10). Thus, its role in removing the organic content from the enamel surface may give valuable results (8).

Espinosa et al (8) concluded that enamel deproteinization with $\mathrm{NaOCl}$ before acid etching doubled the enamel's retentive surface significantly from $48.8 \%$ to $94.47 \%$ and increased the Type I and Type II etching patterns. Also, Garrocho-Rangel et al (11) demonstrated that it improved the sealant retention and adhesion to enamel surface and significantly reduced microleakage. Such effect is due to the ability of $\mathrm{NaOCl}$ to remove the organic material from enamel surface and increase the surface area. However, Bhoomika et al (12), Harleen et al (7) and Ramakrishna et al (13), concluded that the shear bond strength was not improved after enamel deproteinization with $5.25 \% \mathrm{NaOCl}$ and the use of $37 \%$ H3PO4 for 15 seconds still remained the best method for pre-treatment of enamel.

Due to conflict of the results, $5.25 \% \mathrm{NaOCl}$ was reevaluated as a deproteinizing agent prior to acid etching. The null hypothesis was the assumption that deproteinization of human dental enamel surfaces, with $5.25 \% \mathrm{NaOCl}$ before acid etching does not increase the shear bond strength and does not decrease the nanoleakage than traditional acid etching and sealant placement, in permanent teeth.

\section{MATERIALS AND METHODS}

This experimental in vitro study was performed at the Pediatric Dentistry and Dental Public Health Department, Dental Biomaterial Department, Faculty of Dentistry and Electron Microscopy Unit, Faculty of Sciences, Alexandria University.

A sample size of 36 per group (total 72) was the enough required sample to detect a standardized effect size of 0.6 of the primary outcome as statistically significant with $80 \%$ power $(\beta=0.20)$ and at a significance level of $95 \%(\alpha=$ 0.05 ). Sample size per group was increased to 40 per group (total of 80) to control for attrition bias (power=84.49\%).

Eighty non-carious posterior human permanent teeth extracted for orthodontic reasons were collected from the out-patient clinic of the Oral Surgery Department at Faculty of Dentistry, Alexandria University after the approval of the Ethical Committee.

Teeth were cleaned from debris and blood with aqueous slurry of pumice and then stored in physiologic saline at room temperature (14). Teeth included in the study were randomly allocated using permuted block randomization technique (15) into two groups according to the enamel preparation method. Group A: Forty teeth were subjected to enamel deproteinization prior to acid etching. Group B: Forty teeth were subjected to acid etching without deproteinization. Each main group was further divided equally into two subgroups $(n=20)$ according to the test used whether shear bond strength and nanoleakage respectively.

\section{a. Shear bond strength test}

The crowns of 40 teeth were separated from the root $2 \mathrm{~mm}$ below the cementum-enamel junction with a water-cooled, low-speed diamond saw. Each tooth was mounted in self curing acrylic resin with their sound buccal surface displayed perpendicular to the long axis of the block (16). The buccal surfaces were ground flat using 800 and 1000 grit wet silicon carbide finishing paper under water cooling (17).
Subgroup A1: Twenty teeth were deproteinized with freshly prepared 5.25\% NaOCl. It was applied with a sterile cotton for 60 seconds, rinsed with sterile water for 10 seconds and dried thoroughly by oil-free compressed air spray (11). The teeth were then sealed. Subgroup B1: Twenty teeth were sealed with acid etching without deproteinization.

The enamel in both sub-groups was etched with $37 \%$ $\mathrm{H}_{3} \mathrm{PO}_{4}$ gel (Kerr, Orange, CA, USA) for 15 seconds, rinsed for 10 seconds and air-dried for 5 seconds. The sealant (PROMEDICA Dental Material. Domagkstr,31. 24537 Neumunster Germany) was applied to the flattened buccal enamel surface in increments and according to the manufacturers' instructions using a cylindrical plastic tube (4mm in diameter and $3 \mathrm{~mm}$ in height). The plastic tube was perpendicularly centralized over the treated enamel surface and stabilized by sticky wax (18). The plastic mold was then removed carefully and the teeth were left undisturbed for 24 hours in an incubator at $100 \%$ humidity at $37^{\circ} \mathrm{C}$ prior to shear bond strength testing (16).

Each tooth was mounted in a special attachment in a Universal Testing Machine (Instron, Comten Industries, USA). The force was applied with a metallic loading blade placed as close as possible and parallel to the junction of the tested material and the enamel surface with a cross head speed $1 \mathrm{~mm} / \mathrm{min}$. Shear bond strength was then measured by determining the force required to dislodge the sealant from the enamel surface. Bond strength was calculated in Megapascals (MPa) via dividing the load at failure (Newtons) by the adhesive surface area of the attachment $\left(\mathrm{mm}^{2}\right)$ (19).

The fracture assemblies for each tooth were evaluated by a single operator under a stereomicroscope (Olympus Co. Germany) at 40x magnification to determine the location and type of failure according to Peutzfeldt and Nielsen (19) as: cohesive failure (failure occurred within the substrate enamel or sealing material), adhesive failure (between sealing material and enamel) and mixed failure (adhesive and cohesive failures occurred simultaneously).

\section{b. Nanoleakage test}

Forty teeth were mounted in epoxy resin using cuboidal copper molds with the occlusal surface facing upwards and perpendicular to the long axis of the block for nanoleakage evaluation quantitatively using Energy Dispersive X-ray spectrometer (EDX) and qualitatively using Scanning Electron Microscope (SEM) (Joel JSM-5300. Faculty of Science, Alexandria University).

Subgroup A2: Twenty teeth were fissure sealed with deproteinization prior to acid etching.

Subgroup B2: Twenty teeth were fissure sealed after acid etching without deproteinization.

Deproteinization, etching of occlusal surface and sealant application took place as previously mentioned. All sealed teeth were stored in normal saline until thermocycling. Teeth were thermocycled in a water bath between $5^{\circ} \mathrm{C}$ and $55^{\circ} \mathrm{C}$ for 500 cycles with a dwell time of 30 seconds (20).

Staining of teeth: After thermocycling, all sealed teeth were coated with 2 layers of nail varnish over the axial surfaces of each tooth, leaving $1 \mathrm{~mm}$ free around the sealant borders. Teeth were then immersed in freshly prepared silver nitrate solution (50\% by wt) (GAMMA Laboratory Chemicals) for 24 hours in lightproof containers, followed by thorough rinsing with running distilled water for 5 min. The silver nitrate was prepared by dissolving 50 grams of pure silver nitrate in 
$100 \mathrm{ml} / \mathrm{L}$ of distilled water (21). The stained teeth were then immersed for 8 hours in photo developing solution (Carestream Dental X-ray, Belgium) under fluorescent light so that the silver ion reduction to metallic silver would be completed (21). Then teeth were rinsed with distilled water for 5 minutes to remove the photo developing solution. Finally, teeth were dried and sectioned with a water-cooled diamond saw in a buccolingual direction through the sealant resulting in two sections for each specimen (20).

1- Energy dispersive $x$-ray spectrometer (EDX) (quantitative evaluation)

Specimens were dehydrated by immersing in ascending grades of ethyl alcohol (30-70\%) (22), then left to completely dry in fresh air. Then they were mounted each on a copper stub and exposed to the EDX. Elemental distribution of silver (Ag) content in percent (\%) weight of enamel was determined in the form of peaks on a graph with their corresponding readings. Three standard measurements were obtained at three representive points along the enamel sealant interface (I, II, III) on each specimen. The first representive point (I) was measured at the midpoint of the buccal surface of the interface, the second reperesentive point (II) was measured at the midpoint of the lingual surface of the interface and the third representive point (III) was measured at the tip of the apex of the interface. A mean of the three measurements was calculated and represented the total silver \% penetrated the enamel sealant interface of each specimen (23).

2- Scanning electron microscope (qualitative evaluation) Ten specimens (5 from each subgroup A2, B2) were airdried, mounted on an aluminum stub, coated with gold for scanning electron microscope (SEM) examination, and photos of the sections were obtained (24).

\section{Statistical analysis}

Data were collected and entered to the computer using SPSS (Statistical Package for Social Science) program for statistical analysis (ver 21) (25). Data were entered as numerical or categorical, as appropriate. Data were described using minimum, maximum, mean, standard deviation, median and inter-quartile range. Kolmogorov-Smirnov test of normality revealed significance in the distribution of the variables, so the non-parametric statistics was adopted. Categorical variables were described using frequency and percentage. Comparisons were carried out between two studied independent notnormally distributed subgroups using Mann-Whitney U test. Chi square test and Post-hoc analysis was used to compare mode of failure between the two groups. Box and Whiskers plot and clustered bar chart were used accordingly. In the present study, an alpha level was set to $5 \%$ with a significance level of $95 \%$, and a beta error accepted up to $20 \%$ with a power of study of $80 \%$.

\section{RESULTS}

\section{Shear bond strength evaluation}

Mann-Whitney U test showed no statistical significant difference in the median values and interquartile ranges of the shear bond strength between experimental (A1) and control (B1) subgroups $(\mathrm{P}=0.678)$ (Table 1 , Figure 1$)$.
Table (1): Comparison of shear bond strength (MPa) between experimental and control groups.

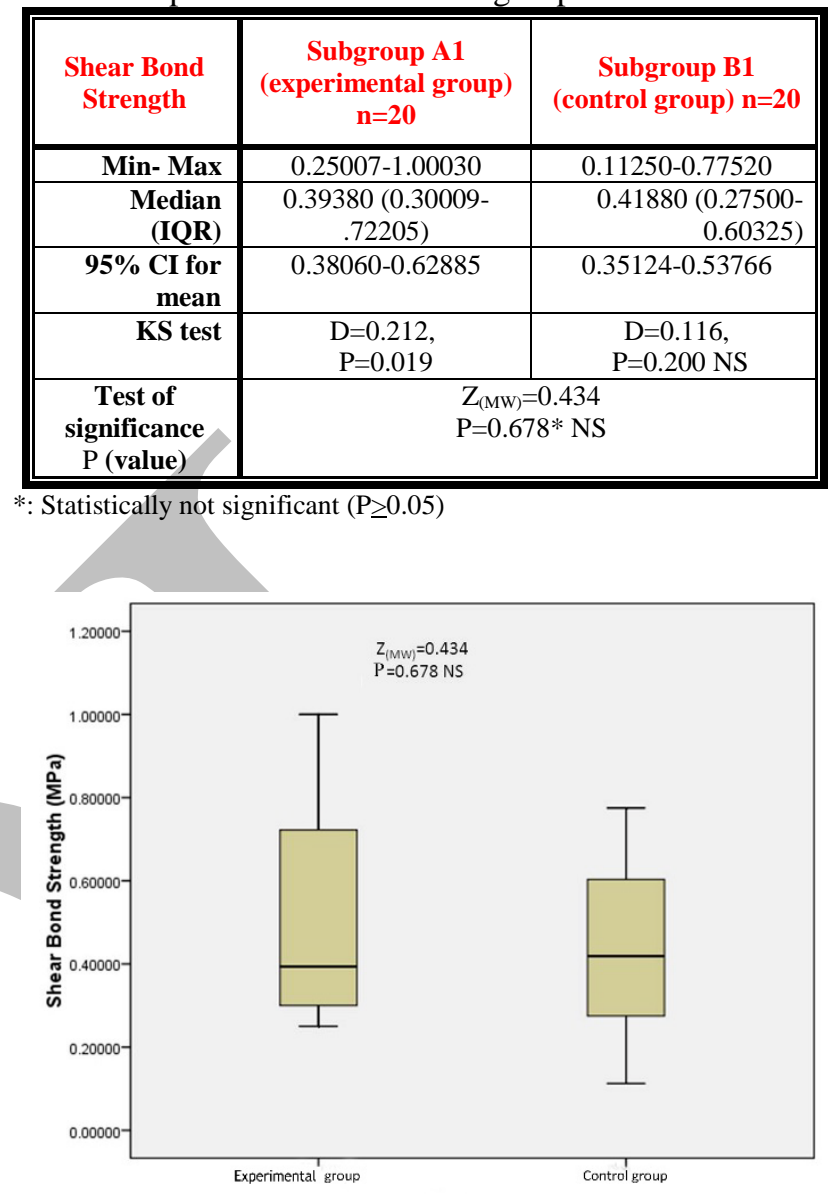

Figure 1: Box and whisker graph of shear bond strength (MPa) in subgroups A1and B1.

Regarding the mode of failure chi square test and post-hoc analysis showed that in subgroup A1 (experimental group) $45 \%$ had cohesive mode of failure and 55\% had mixed mode failure, while in subgroup B1 (control group), $60 \%$ had cohesive mode of failure and $40 \%$ had mixed mode of failure. There was no statistically significant difference in distribution of modes of failure between the two subgroups with $(\mathrm{P}=0.342)$. (Table 2, Figure 2)

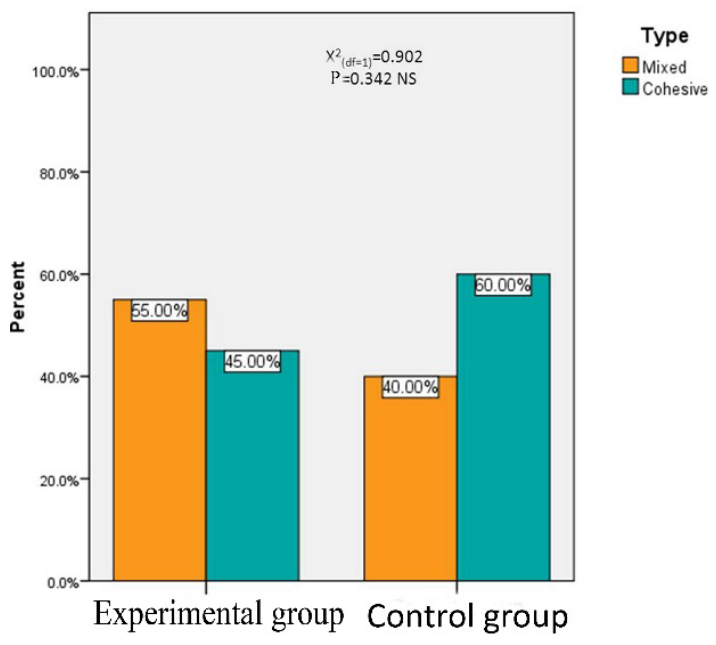

Figure 2: Bar graph representing the mode of failure in subgroups A1and B1. 
Table (2): Comparison of mode of failure between experimental and control groups.

\begin{tabular}{||c|c|c|c||}
\hline Mode of failure & $\begin{array}{c}\text { Subgroup A1 } \\
\text { (experimental } \\
\text { group) } \\
\mathbf{n = 2 0}\end{array}$ & $\begin{array}{c}\text { Subgroup } \\
\mathbf{B} 1 \\
\text { (control } \\
\text { group) } \\
\mathbf{n = 2 0}\end{array}$ & $\begin{array}{c}\text { Test of } \\
\text { significance } \\
\mathbf{p} \text { (value) }\end{array}$ \\
\hline Mixed - & $11(55.00 \%)$ & $8(40.00 \%)$ & $\begin{array}{c}\mathrm{X}^{2}(\mathrm{~d}=1)=0.902 \\
\mathrm{P}=0.342^{*} \mathrm{NS}\end{array}$ \\
\hline Cohesive - & $9(45.00 \%)$ & $12(60.00 \%)$ & \\
\hline
\end{tabular}

\section{Nanoleakage evaluation}

a. Energy dispersive x-ray spectrometer (EDX) (quantitative evaluation)

The median values and interquartile ranges of the silver penetration percentages of the total examined interface for the experimental and control groups are shown in Table 3, Figure 3, and the result showed that there was a statistically significant difference in nanoleakage score between the experimental and control groups. Subgroup A2 (experimental group) showed significant lower nanoleakage scores than subgroup B2 (control group) $(\mathrm{P}<0.001)$

b. Scanning electron microscope (qualitative evaluation) The images obtained showed little penetration of silver nitrate at the bonding interfaces between the sealant and enamel in the experimental group (Figure 4), in comparison with the control group, which showed more silver penetration especially at the base of the fissure (Figure 5)

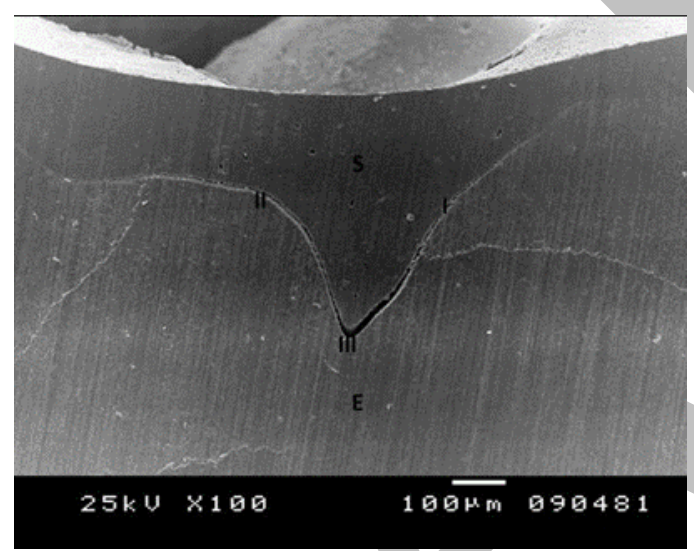

Figure 5: Scanning electron micrograph of the enamel sealant interface for subgroup B2 and the three representive points I, II, III at magnification $\times 100$. ( $\mathrm{E}=$ enamel, $\mathrm{S}=$ sealant $)$

\section{DISCUSSION}

The results of the present study rejected the null hypothesis, which had assumed that deproteinization of human dental enamel surfaces; with $5.25 \% \mathrm{NaOCl}$ before etching did not increase the shear bond strength and did not decrease the nanoleakage than traditional acid etching and sealant placement, in permanent teeth.

In the present study, there was no significant difference in shear bond strength between the experimental and control group. Sodium hypochlorite was intended to remove the organic material from the enamel surface. The organic material compromises only $1 \%$ of the enamel, however it may affect the quality of etching pattern. Our results showed that the removal of the organic content increased the shear value despite the fact that it did not reach a statistically significant figure.
Bhoomika et al (12), Harleen et al (7) and Ramakrishna et al (13), stated that the shear bond strength was not improved after enamel deproteinization with $5.25 \% \mathrm{NaOCl}$ and the use of $37 \% \mathrm{H}_{3} \mathrm{PO}_{4}$ for 15 seconds still remained the best method for pre-treatment of enamel. Also, Gandhi et al (26) concluded from their study that there was no significant difference in the tag quality between acid etch only and deproteinization before acid etching.

On the contrary, Espinosa et al (8) showed that removing organic content from the enamel surface with $5.25 \% \mathrm{NaOCl}$ as a deproteinizing agent prior to acid etching, doubled the enamel's retentive surface significantly from $48.8 \%$ to $94.47 \%$ and increased the TypeI and Type-II etching patterns which were considered to be the most retentive patterns of acid etching. Again, Espinosa et al (27) evaluated the qualitative and quantitative resin tag penetration with a resin replica model and concluded that enamel deproteinization with $5.25 \% \mathrm{NaOCl}$ for 60 seconds prior to $\mathrm{H}_{3} \mathrm{PO}_{4}$ etching almost doubled the enamel's retentive surface from $46 \%$ to $73 \%$ and the topographical features of the replica resin penetration surface increased significantly with Type-I and Type-II etching patterns.

With regard to the types of failures observed in the fractured specimens, cohesive and mixed failure patterns were predominantly observed in the 2 groups with no significance difference between them which supported our previous finding that both groups had same bond strength, while adhesive mode of failure was not found which indicated high strength in both groups.

To evaluate the sealing ability of sealant, nanoleakage represented a refined means of assessing the defective adaptation of materials more than traditional microleakage tests. (28). Silver nitrate has been accepted as a suitable method for measuring interfacial leakage due to the size of silver ion dyes compared to the size of typical bacterium $(0.5-1.0 \mathrm{~nm})$ (30). Most nanoleakage studies are performed on dentin surface. However, in our study we evaluated nanoleakage on enamel surface which represented a clinically relevant case. The use of SEM in conjunction with EDX to measure the nanoleakage qualitatively and quantitatively respectively enabled distinct images to be captured together with sensitive and accurate analysis (29).

In order to simulate changing intraoral temperature conditions and create the aging effects that restorative materials are prone to in the oral cavity, all teeth were subjected to thermocycling between $5^{\circ} \mathrm{C}$ and $55^{\circ} \mathrm{C}$ for 500 cycles (30).

When the nanoleakage patterns between the sealant and enamel were evaluated quantitatively, the experimental group showed less silver tracing than that of the control group. Results revealed a statistically significant lower nanoleakage score for experimental group, and indicated adequate bonding and sealing ability, that prevented the infiltration of silver ions inside the interface.

Concerning the qualitative evaluation of nanoleakage by SEM, the images obtained showed little penetration of silver nitrate at the bonding interfaces between the sealant and enamel in the experimental group, as compared to the control group which showed more silver penetration specially at the base of the fissure as shown by SEM in the Figure 5.

These quantitative and qualitative results indicated that deproteinization before acid etching perform adequate bonding and sealing ability as it prevented the infiltration of 
silver ions inside the interface. The reason behind these findings may be due to the removal of organic material which allowed more surface area and thus better sealing. This finding was supported by Garrocho-Rangel et al(11), who compared the microleakage of sealant after placement on etched enamel with and without deproteinization. They stated that microleakage was significantly reduced in deproteinization group.

Permanent teeth were used in the present study as the focus of most sealant studies is on the occlusal surfaces of permanent molars, especially permanent first molar which is the most susceptible for occlusal caries because of variation in occlusal fissure morphology and long eruption phase $(31,32)$.

One of the limitations of this study is that in vitro setting may not simulate the effect of deproteinization and acid etching in vivo, and the clinical condition in the mouth is not easy to imitate in the laboratory. In addition, possible concerns of $\mathrm{NaOCl}$ are the taste, chlorinated odor, tolerance by young children and possible soft tissue reactions (8).

The overall results of the present study indicated that deproteinization group had comparable shear bond strength but lower nanoleakage than that of the control group.

\section{CONCLUSION}

Within the limitations of the present study it may be concluded that deproteinization prior to acid etching slightly improved shear bond strength. However, it showed a significant reduction in sealant nanoleakage when compared to acid etching only.

\section{CONFLICT OF INTEREST}

The authors declare that they have no conflict of interest.

\section{REFERENCES}

1. Nardi GM, Mazur M, Corridore D, Capocci M, Rinaldo FM, Maruotti A et al. Clinical comparison between an opaque and a clear pit and fissures sealants: a 12-month split-mouth, randomized controlled study. Clin Ther. 2018;169:e5-e9.

2. Agarwal A, Shigli A. Comparison of six different methods of cleaning and preparing occlusal fissure surface before placement of pit and fissure sealant: An in vitro study. J Indian Soc Pedod Prev Dent. 2012;30:51-5.

3. Bravo M, Montero J, Bravo JJ, Baca P, Llodra JC. Sealant and fluoride varnish in caries: a randomized trial. J Dent Res. 2005;4:1138-43.

4. Borsatto MC, Corona SA, Dibb RG, Ramos RP, Pécora JD. Microleakage of a resin sealant after acid-etching, Er:YAG laser irradiation and air-abrasion of pits and fissures. J Clin Laser Med Surg. 2001;19:83-7.

5. Sano H, Takatsu T, Ciucchi B, Horner JA, Matthews WG, Pashley DH. Nanoleakage: leakage within the hybrid layer. Oper Dent. 1995;20:18-25.

6. Buonocore MG. A simple method of increasing the adhesion of acrylic filling materials to enamel surfaces. J Dent Res. 1955;34:849-53.

7. Harleen N, Ramakrishna Y, Munshi AK. Enamel deproteinization before acid etching and its effect on the shear bond strength - an in vitro study. J Clin Pediatr Dent. 2011;36:19-23.

8. Espinosa R, Valencia R, Uribe M, Ceja I, Saadia M. Enamel deproteneization and its effect on acid etching:
An in vitro study. J Clin Pediatr Dent. 2008;33:13-20.

9. Hobson RS, Crotty T, Thomason JM, Jepson NJ. A quantitative study of enamel acid etch patterns on surfaces used for retention of resin- bonded fixed prostheses. Eur J Prosthodont Restor Dent. 2005;13:1238.

10. Abdelmegid FY. Effect of deproteinization before and after acid etching on the surface roughness of immature permanent enamel. Niger J Clin Pract. 2018;21:591-6

11. Garrocho-Rangel A, Lozano-Vázquez C, Butrón-TellezGirón C, Escobar-García D, Ruíz-Rodriguez S, PozosGuillén A. In vitro assessment of retention and microleakage in pit and fissure sealants following enamel pre-etching with sodium hypochlorite deproteinisation. Eur J Paediatr Dent. 2015;16:212-6.

12. Bhoomika A, Ramakrishna Y, Baliga MS, Munshi AK. Enamel deproteinization before acid etching - a Scanning electron microscopic observation. J Clin Pediatr Dent. 2010;35:169-72.

13. Ramakrishna Y, Bhoorsika A, Harleen N, Munshi AK. Enamel deproteneization after acid etching - Is it worth the effort? Dentistry. 2014;4:200-4.

14. Hatibovic-Kofman S, Butler SA, Sadek H. Microleakage of three sealents followed by Conventional, bur and air abrasion preparation of pit and fissure. Int J Peadiatr Dent. 2001;11:409-16.

15. Schulz KF, Grimes DA. Generation of allocation sequences in randomised trials: chance, not choice. Lancet. 2002;359:515-9.

16. Margvelashvili M, Vichi A, Carrabba M, Goracci C, Ferrari M. Bond strength to unground enamel and sealing ability in pits and fissures of a new self-adhering flowable resin composite. J Clin Pediatr Dent. 2013;37:397-402.

17. Ellis RW, Latta MA, Westerman GH. Effect of air abrasion and acid etching on sealant retention: an in vitro study. Pediatr Dent. 1999;21:316-9.

18. Sharaf A. The use of a self-etching adhesive in the application of pit and fissure sealant: an in vivo and in vitro study. Egy Dent J. 2003;49:1319-26.

19. Peutzfeldt A, Nielsen LA. Bond strength of a sealant to primary and permanent enamel: phosphoric acid versus self-etching adhesive. Pediatr Dent. 2004;26:240-4.

20. Pardi V, Sinhoreti MA, Pereira AC, Ambrosano GM, Meneghim Mde C. In vitro evaluation of microleakage of different materials used as pit and fissure sealants. Braz Dent J. 2006;17:49-52.

21. Tay FR, Pashley DH, Yoshiyama M. Two modes of nanoleakage expression in single-step adhesives. J Dent Res. 2002;81:472-6.

22. De Carvalho Filho AC, Sanches RP, Martin AA, Do Espírito Santo AM, Soares LE. Energy dispersive X-ray spectrometry study of the protective effects of fluoride and varnish and gel on enamel erosion. Microscc Res Tech. 2011;74:839-44.

23. El-Badrawy W, Hafez RM, Abo El Naga AI, Ahmed DR. Nanoleakage for Self-Adhesive Resin Cements used in Bonding CAD/CAD Ceramic Material to Dentin. Eur J Dent. 2011;5:281-90.

24. Atwan SM, Sullivan RE. In vitro evaluation of the tensile bond strength of a chemically initiated and a visibly initiated sealant with SEM observations. Pediatr Dent. 1987;9:147-51.

25. IBM Corp. IBM SPSS Statistics for Windows, Version 21.0. Armonk, NY: IBM Corp.; Released 2012. 
26.Gandhi S, Crawford P, Shellis P. The use of a 'bleach etch - seal' deproteinization technique on MIH affected enamel. Int J Pediatr Dent. 2012;22:427- 34.

27.Espinosa R, Valencia R, Uribe M, Ceja I, Cruz J, Saadia M. Resin Replica in enamel deproteinization and its effect on acid etching. J Clin Pediatr Dent. 2010;35:47-52.

28. Fouad W, El Motayam KM, Youssef R. Assessment and Comparison of Nanoleakage and Resin Tag Length of Three Different Pit and Fissure Sealants: An In-Vitro Scanning Electron Microscope Study. J Am Sci. 2013;9:329-37.

29.Prieto LT, Souza-Júnior EJ, Araújo CT, Lima AF, Dias CT, Paulillo LA. Nanoleakage evaluation of resin luting systems to dental enamel and leucite-reinforced ceramic. Microsc Res Tech. 2012;75:671-6.

30.Yavuz I, Aydin AH, Ulku R, Dulgergil TC, Akdag MZ. New technique: Measurement of microleakage volume in the marginal gaps of the dental restorations. Biotechnol Biotech Eq. 2005;19:184-91.

31.Naaman R, El-Housseiny AA, Alamoudi N. The Use of Pit and Fissure Sealants-A Literature Review. Dent J (Basel). 2017;5:pii:E34.

32.Babaji P, Vaid S, Deep S, Mishra S, Srivastava M, Manjooran T. In vitro evaluation of shear bond strength and microleakage of different pit and fissure sealants. J Int Soc Prev Community Dent. 2016;6:S111-5

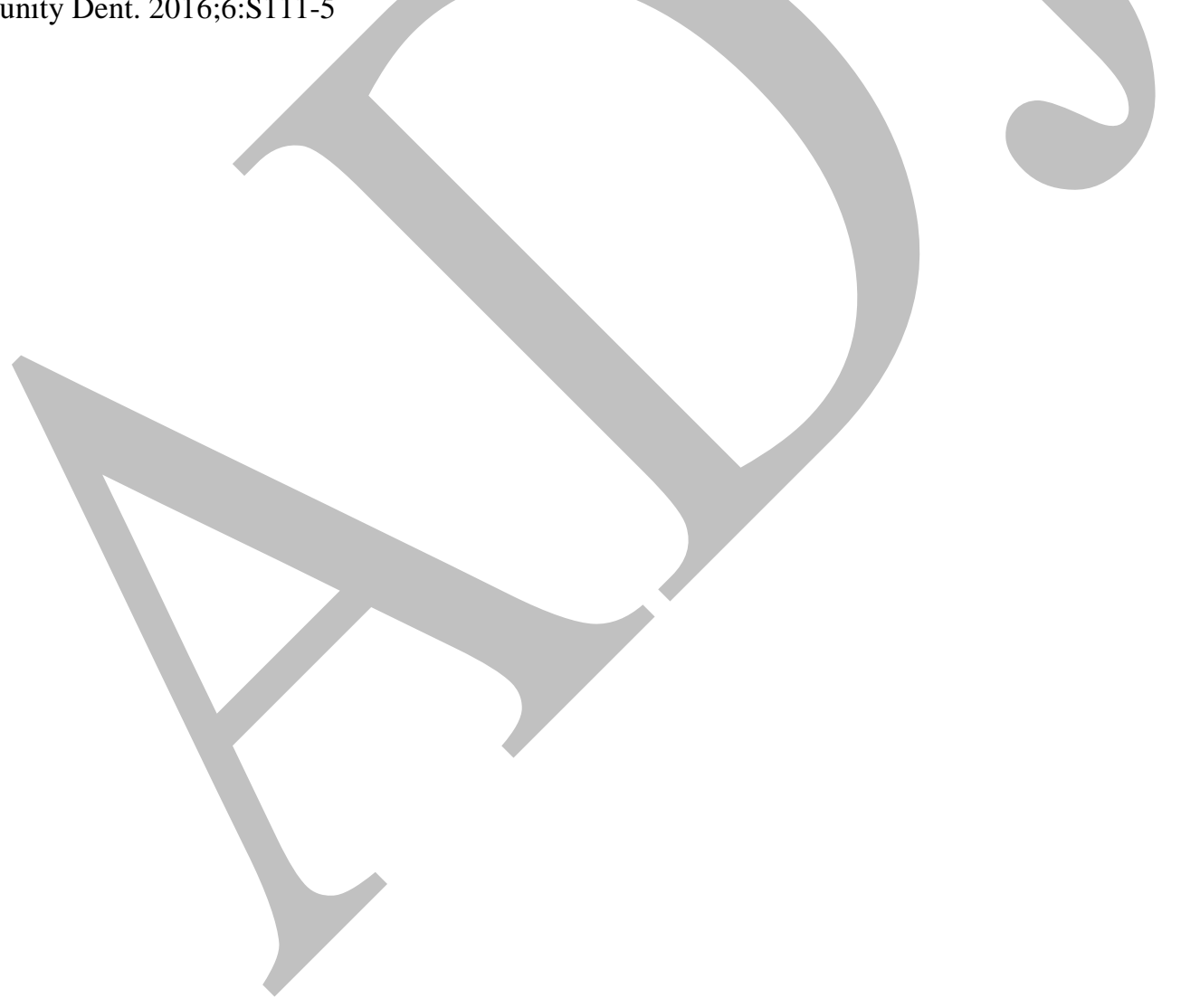

